\title{
Underestimating Our Influence Over Others at Work
}

Vanessa K. Bohns, University of Waterloo

Francis J. Flynn, Stanford University

Published in Research in Organizational Behavior

Corresponding Author:

Vanessa K. Bohns

Department of Management Sciences

University of Waterloo

200 University Avenue West

Waterloo, Ontario, Canada N2L 3G1

vbohns@uwaterloo.ca 


\begin{abstract}
Employees at all organizational levels have influence over their subordinates, their colleagues, and even their bosses. But are they aware of this influence? We present evidence suggesting that employees are constrained by cognitive biases that lead them to underestimate their influence over others in the workplace. As a result of this underestimation of influence, employees may be reluctant to spearhead organizational change, discount their own role in subordinates' performance failures, and fail to speak up in the face of wrongdoing. In addition to reviewing evidence for this bias, we propose five moderators that, when present, may reverse or attenuate the underestimation effect (namely, comparative judgments, the objectification or dehumanization of an influence target, the actual degree of influence any one influencer has, the means of influence, and culture). Finally, we offer some practical solutions to help employees more fully recognize their influence over other members of the organization.
\end{abstract}




\section{Contents}

1. Our Extraordinary Influence Over Others at Work

1.1 Downward Influence

1.2 Lateral Influence

1.3 Upward Influence

2. Do We Recognize Our Influence Over Others at Work?: Two Hypotheses

2.1 The Overestimation Hypothesis

2.2 The Underestimation Hypothesis

2.3 Empirical support for the underestimation hypothesis

3. Underestimating Our Influence Over Others at Work

3.1 Organizational Implications: Three Examples

3.3.1 Organizational Change

3.3.2 Performance Appraisal

3.3.3 Whistle-Blowing

4. Reconciling Underestimation with the Overestimation Hypothesis

4.1 Theoretical Reconciliations of the Two Hypotheses

4.2 Possible Moderating Factors

4.2.1 Comparative Judgments

4.2.2 Objectification or Dehumanization of the Influence Target

4.2.3 The Influencer's Actual Degree of Influence

4.2.4 The Means of Influence

4.2.5 Culture

5. Discussion 


\subsection{Practical Solutions}

\subsection{Suggestions for Future Research}

\section{Conclusion}

\section{References}


Researchers in organizational behavior usually approach the topic of social influence by documenting its existence. For example, they investigate how much influence a manager has over his or her subordinates, how much power a well-connected member of a social network can wield, or even how much sway low-level employees enjoy over their superiors. This work demonstrates, in a convincing fashion, that individual members of organizations have a substantial amount of influence over their subordinates, their colleagues, and even their bosses. We approach the topic of social influence from a different point of view-we investigate whether people are aware of the influence they have over others in the workplace. We suggest they are not. Rather, individual employees may be constrained by cognitive biases that lead them to underestimate their influence over coworkers.

This underestimation bias has important practical implications. Managers who do not recognize the full extent of their power may be reluctant to champion important new initiatives. Colleagues who do not appreciate their sway over one another may abandon any hope of improving a difficult working relationship. Subordinates who do not understand the influence they have over their bosses may come across as demure and uninspired. In short, many valuable endeavors that could be accomplished in the workplace will never materialize because they are assumed to be impossible, or at least improbable. As with many cognitive biases, such shortsightedness can be improved by training individuals to account for their blind spots. Illuminating the actual influence employees have over one another can embolden them to wield such influence in productive ways.

We begin by reviewing empirical evidence that illustrates the influence possessed by employees at all organizational levels. In addition to obvious forms of downward influence (e.g., legitimate power), theories of referent power, social exchange, conformity, and role expectations 
offer compelling examples of lateral and upward influence. We then describe two hypotheses that make competing predictions about the extent to which employees are likely to recognize the influence they have other others at work. The first hypothesis, the overestimation hypothesis, emanates from research on overconfidence, illusory control, and false consensus, which suggests that employees will have an inflated view of their influence over coworkers. The second hypothesis, the underestimation hypothesis, emanates from research on egocentrism and attribution theory, which suggests that employees will not fully appreciate their influence over coworkers. We then present evidence that supports the underestimation hypothesis and an explanation for why this hypothesis may be better able to account for existing data. However, given that individuals will sometimes overestimate their influence, we also propose five moderators of the underestimation bias that may reverse or attenuate the effect. Finally, we offer some practical implications to illustrate how the underestimation of influence may play out in the workplace along with solutions to help employees more fully recognize their influence over other members of the organization.

\section{Our Extraordinary Influence Over Others at Work}

Every employee — from a lowly placed intern to a highly perched CEO — has the potential to influence the attitudes, values, and behaviors of his or her coworkers (Kipnis, Schmidt, \& Wilkinson, 1980). On one hand, for those sitting atop the organizational hierarchy, such influence may primarily come from their position of authority - they have legitimate power over the actions of their subordinates. Yet, a senior executive's influence can extend beyond that individual's legitimate authority, affecting, for example, how employees go about leading their personal lives. On the other hand, for those sitting on the bottom rungs of the organizational ladder, they may influence others through more informal means, such as modeling behaviors that 
are viewed favorably (e.g., treating people with dignity and respect or promoting the firm's reputation). In short, organizations are social environments complete with exchange norms, conformity pressures, and role expectations, which apply to everyone and afford considerable influence. In this section we provide some illustrative evidence of such influence.

\subsection{Downward Influence}

"[I]f Wintour [asks] for something, there aren't two possible answers. 'If I get a request for something I don't want to do,' says Marc Jacobs, '... I don't even bother to say no.' - J. Levine, Wall Street Journal, March 23, 2011

Anna Wintour, editor-in-chief of American Vogue, has famously purged her employees' wardrobes of the color black (Jacobs, 2012) and led renowned, independent fashion designers to change their designs with a single disparaging sentence (Cutler, 2009). Her position at the top of the fashion industry's social hierarchy has given her extraordinary power, which she wields liberally. But even bosses less totalitarian than Wintour possess a surprisingly far-reaching sphere of influence over their subordinates. By virtue of their position, bosses typically have some control over employees' salaries, permitted time off, and daily responsibilities. They may request that their employees stay late or work over the weekend. Their impact can creep into employees' personal lives, affecting their mental and physical health (Blanchard, 1993). On the positive side, supportive managers are associated not only with greater job satisfaction, but also lower levels of work-family conflict, depression, somatic complaints, and even blood cholesterol (Thomas \& Ganster, 1995). Conversely, bad bosses can make employees miserable, exerting a larger influence on employee dissatisfaction than pay, benefits, or vacation time (Zenger \& Folkman, 2012). Such dissatisfaction often extends beyond the workplace into personal feelings 
about one's life and subjective wellbeing (Adams, King, \& King, 1996; Judge, Locke, Durham, \& Kluger, 1998).

Bosses can also affect employees' attitudes and values, even their willingness to engage in ethically questionable behaviors. At the extreme are "crimes of obedience," which are illegal or immoral acts performed in response to orders from an authority figure (Hamilton \& Sanders, 1992; Kelman \& Hamilton, 1989). When committing such “crimes,” employees may disavow their responsibility for the act because they were simply following a superior's orders; or, their values may shift as a result of a boss's convincing rationalizations (Ashford \& Anand, 2003; Brief et al., 1995; Brief et al., 2001; Darley, 2001). Simon (1976) has described the obedience of a subordinate to a legitimate authority as "hold[ing] in abeyance [one's] own critical facilities for choosing between alternatives and us[ing] the formal criterion of the receipt of a command or signal as [one's] basis for choice" (p. 126, as cited in Brief et al., 2000, p. 76-77). An alternative depiction of obedience to authority has been proposed by Beu and Buckley (2004) who have suggested that leaders with political skill are able to convey a vision that inspires followers and leads them to interpret ambiguous situations in ways that make unethical behavior seem acceptable, even desirable. Of course, leaders can also use their influence to inspire employees to behave more ethically (DeCremer \& Tenbrunsel, 2012). For example, groups led by an individual who reasoned in a highly principled manner have been shown to display superior performance in moral decision-making tasks (Dukerich, Nikols, Elm, \& Vollrath, 1990).

The tremendous power of downward influence has a long history in behavioral science. Milgram's (1963) seminal studies of obedience demonstrated that ordinary individuals will agree to administer a dangerous amount of pain to another person simply because an authority figure (i.e., an experimenter in a white lab coat) encouraged them to do so. In the original experiments, 
as well as their modern replications (Burger, 2009), approximately 65\% of participants continue to administer shocks even as the other participant purportedly protests, complains of a heart condition, and then falls silent (Milgram, 1963; Blass, 1999; Burger, 2009). Video of the experiment shows participants repeatedly protesting, yet nonetheless complying with, the experimenter's request (Gibney, 2006). This extreme power possessed by people in authority positions has been used to explain a variety of organizational calamities and crimes ranging from the Ford Pinto gas tank fiasco (Jones \& Ryan, 1998; see Gioia, 1992, for an alternative explanation of the Pinto fiasco) to the downfall of Enron (Gibney, 2005). The upshot of such events is clear: people in authority positions have an extraordinary amount of influence over their subordinates.

\subsection{Lateral Influence}

“Thinking, as yet, was a feat beyond my reach. I had no base, no grounding. My only hope was to watch the salesmen around me and gather what advice I could. Learning what to do meant learning an attitude: learning how to sound on the telephone, how to deal with traders..."

- M. Lewis, 2010, Liar's Poker, p. 195

When thinking of influence, we typically think of the influence that comes from having authority. But, of course, authority is not the only source of influence. We are constantly influencing our coworkers, colleagues, and friends through basic social processes such as conformity pressures, persuasive appeals, and social norms (for a comprehensive review of social influences on ethical behavior, see Moore and Gino, 2013, this issue). In the example described above, Michael Lewis describes how he learned the ropes at Salomon Brothers in 
London, as so many employees do, simply by observing the social norms displayed by those around him.

When individuals encounter an ambiguous situation, they often look to their peers for help in deciding what to do. For example, Gino, Ayal, and Ariely (2009) found that students who saw a fellow student cheat on a task were more likely to cheat as well. Indeed, when we see someone who has transgressed, especially when we feel close to that person, we reinterpret the offense as being less unethical and consequently feel more comfortable engaging in the same act ourselves (Gino \& Galinsky, 2012).

We are also likely to follow suit when we see people engaging in positive behaviors. For example, Nolan, Schultz, Cialdini, Goldstein, and Griskevicius (2008) conducted an intervention aimed at increasing people's conservation behavior. In a community of households in California, the researchers placed paper "doorhangers" on the front doors of people's homes. The doorhangers contained factual information about either how one's conservation behaviors would impact the environment, or what one's neighbors were doing to conserve. The results indicated that normative information - descriptive statistics about what other people were doing - was far superior to information about the effect of one's behaviors on the environment for positively influencing energy conservation.

Similar effects of peer influence have been demonstrated in the workplace. In two samples of employees at advertising agencies, Zey-Ferrell and Ferrell (1982) found that employees' impressions of the ethical attitudes and behaviors of their peers were the strongest predictor of how often they engaged in unethical behaviors like calling in sick to take a day off, concealing errors, and padding expense accounts. In fact, employees' beliefs about what their 
peers thought was a better predictor of their unethical behaviors than their beliefs about what their bosses and agencies thought of these transgressions.

Peer influence has long captured the interest of behavioral scientists. According to social learning theory (Bandura \& McClelland, 1977), observing the behavior of our peers teaches us (a) what to do in a given situation, and (b) what the consequences of our actions are likely to be. Classic examples of peer influence include Solomon Asch's $(1951 ; 1956)$ discovery that individuals will conform to a blatantly incorrect group opinion, Latane and Darley’s (1970) finding that people will look to others to decide how they should behave in an emergency situation, and Cialdini, Reno, and Kallgren's (1990) revelation that telling people not to litter is useless if they see others doing so. Of course, the flip side of the great amount of influence our peers have over us is the great amount of influence we have over them. Just as we look to others to decide what constitutes acceptable behavior, others regularly look to us.

\subsection{Upward Influence}

"I'm more of a delegator with a decentralized approach to the business."

-Kenneth Lay (former Chairman of Enron)'s testimony as reported on Bloomberg.com, April 24, 2006

We have described the influence of authority figures on subordinates and the mutual influence of equal-status peers. We now turn to the influence that subordinates have over their superiors. As reflected in Kenneth Lay's testimony above, upward influence may occur through formal means such as subordinates' performance of delegated tasks (Heller \& Yukl, 1969; Locke \& Schweiger, 1979) or participation in executive decision-making (Schweiger \& Leana, 1986). 
Subordinates' roles as intermediaries and their consequent control over information and connections may garner them substantial influence over their bosses (Mechanic, 1962).

However, upward influence may also occur through more subtle social channels of influence. To wit, leaders are subject to the same social influences as their subordinates and colleagues (albeit to a lesser degree; Galinsky, Magee, Gruenfeld, Whitson, \& Liljenquist, 2008).

The reciprocal nature of the leader-follower relationship has been discussed in the organizational behavior literature as early as 1955 (Hollander \& Webb, 1955). It is now widely accepted that not only do leaders influence their followers, followers in turn influence their leaders (Avolio, 2007; DeCremer \& Tenbrunsel, 2012; Herold, 1977; Hollander and Julian, 1969). According to Hollander (1958), followers bestow onto leaders "credits" that can be withheld or reneged for "failing to fulfill followers' role expectations, including inaction in the face of need, self-serving and other negatively viewed behaviors, and perceptions of weak motivation, incompetence, and responsibility for failure (cf. Alvarez, 1968)" (Hollander \& Offerman, 1990, p. 181). In other words, followers confer legitimacy on their leaders, and if a leader fails to meet his followers' expectations, this legitimacy can be revoked along with the leader's influence (Tyler, Boeckmann, Smith, \& Huo, 1997). In this way, a leader's behaviors are always determined in part by the expectations of his or her followers.

Subordinates may also use a variety of influence tactics to elicit specific behaviors from their superiors ranging from direct influence attempts to more subtle forms of manipulation in which one's attempt to influence is concealed (Kipnis \& Schmidt, 1988; Kipnis, Schmidt, \& Wilkinson, 1980; Mowday, 1978; Yukl \& Falbe, 1990). For example, subordinates may use explicit ingratiation and flattery to ask for personal advantages (e.g., a raise or time off; Kipnis \& Schmidt, 1988; Kipnis, Schmidt, \& Wilkinson, 1980). They may directly influence 
organizational outcomes by openly rationalizing with and persuading their superiors (Ansari \& Kapoor, 1987). Followers can also influence leaders' behaviors through more indirect means, such as modeling, guiding, and sense-making behaviors - behaviors a trusted advisor might perform (DeCremer \& Tenbrunsel, 2012).

Upward and lateral influence tactics can even impact the most powerful individual in the American political system. John F. Kennedy's decision on a course of action in Vietnam likely came about as a result of direct persuasion from his advisors (Offerman, 2004). Further, Franklin D. Roosevelt's policies were greatly influenced by Eleanor Roosevelt, his wife. Eleanor displayed a dedication to overlooked issues that FDR admired (an example of referent power and modeling). She opened her husband's eyes to previously ignored or discounted social issues (i.e., guiding), and helped him make sense of complex situations by providing her own interpretation (sense-making) (Cain, 2012). Likewise, subordinates can have a great deal of influence over their superiors, regardless of their relative position in the hierarchy.

\section{Do We Recognize Our Influence Over Others at Work?: Two Hypotheses}

In this section, we turn to the question of whether we recognize the extent of our influence when we are in a position to affect others. We present two plausible answers to this question. The first answer, the overestimation hypothesis, suggests that this influence is highly salient to us; in fact, we may exaggerate our ability to influence others. This hypothesis follows from research on overconfidence, illusory control, and false consensus. The second answer, the underestimation hypothesis, suggests that in many ways we are blind to the amount of influence we have over others. The latter hypothesis follows from research on egocentrism and attribution theory. After reviewing these two competing predictions, we review empirical evidence that appears to offer greater support for the underestimation hypothesis. 


\subsection{The Overestimation Hypothesis}

The overestimation hypothesis suggests that we are not just aware of the influence we have over others; rather, we may overestimate our influence. This hypothesis stems from the fact that in addition to actually being influential, we also like to feel influential as we navigate our social world. The desire to control one's surroundings is a fundamental human motivation (Fiske, 2002; Kelley, 1971). Indeed, our survival partly depends on how effectively we are able to influence our environment in order to receive valued resources. Further, the more we believe in our ability to do so, the better our mental health (Abramson, Seligman, \& Teasdale, 1978; Ackerman \& DeRubeis, 1991; Alloy \& Abramson, 1979; Alloy, Abramson, \& Viscusi, 1981; Rotter 1966; Taylor \& Brown, 1988) and physical health (Lowery, Jacobsen, \& DuCette, 1993; Reed, Taylor, \& Kemeny, 1993; Schulz \& Decker, 1985; Thompson, Nanni, \& Levine, 1994).

The desire to control our surroundings is so great that we often believe we are influencing outcomes that are clearly beyond our control. This "illusion of control" leads people to assume they can increase their chances of winning the lottery by personally selecting their own lottery tickets (Langer, 1975), control the chance outcomes of coin tosses (Langer \& Roth, 1975), and cause the occurrence of non-contingent outcomes (e.g., pressing a button can influence a randomly generated light; Alloy \& Abramson, 1979). Research suggests the illusion of control is particularly strong for situations that mimic the typical conditions of skill-based tasks (i.e., tasks that are familiar, highly involving, competitive, or in which the participant is asked to make a choice, Thompson, Armstrong, \& Thomas, 1998). However, it may also affect other judgments, like our overoptimistic assessments that we are less likely than others to have a variety of uncontrollable negative events happen to us (e.g., getting into a car accident as a passenger; McKenna, 2011). Research on magical thinking has similarly shown that individuals often infer 
that they caused a turn of events in domains ranging from sporting outcomes to voodoo hexes simply by wishing for something to occur (Pronin et al., 2006).

Given the enormous role of the control motive, it would be surprising if this motive, and the corresponding tendency to exaggerate how much control we have in a given situation, did not extend to interpersonal relations, and specifically how much control, or influence, we have over other people. If we believe that we control our environment, then we must believe that we can influence the people who are part of that environment. Moreover, social interactions are similar, in many ways, to the human skills tested in demonstrations of illusory control: they are familiar, they are involving, and they can be competitive (Thompson, Armstrong, \& Thomas, 1998). Thus, it seems reasonable to assume that people may overestimate the level of control they have over others' attitudes, feelings, and behaviors.

If people overestimated their control over others, this would also be consistent with research showing that people are generally overconfident (for reviews see Alicke \& Govorun, 2005 and Dunning, Heath, \& Suls, 2004). For example, people overestimate their cognitive (Ehrlinger \& Dunning, 2003), athletic (Dunning, Meyerowitz, \& Holzberg, 1989), and person perception skills (Swann \& Gill, 1997). Such overconfidence may exist because it can help us maintain our self-esteem (Dunning, Leuenberger, \& Sherman, 1995), lead us to remember our successes more vividly than our failures (Miller \& Ross, 1975), or elevate our status by appearing more competent to others (Anderson, Brion, Moore, \& Kennedy, in press). Regardless of why overconfidence persists, the literature on this effect provides no noteworthy reason for why such a bias would not extend to people's estimates of their influence abilities.

A third area of research that supports the overestimation hypothesis is social projection, and in particular the false consensus bias (Ross, Greene, \& House, 1977; for a review see 
Krueger \& Clement, 1997). False consensus describes an individual's tendency to assume, often incorrectly, that others share the focal individual's attitudes and values. As a result, we are likely to underestimate the amount of effort it will take to get others to see things our way. That is, we may assume that we don't have to push other people very far in their attitudes or values in order to get them to see things from our perspective (e.g., "If I just lay out the facts, she'll obviously agree that this is the right thing to do"). Because we are likely to underestimate how hard we have to work to persuade others, we may therefore be overconfident in the efficacy of our persuasive skills.

Taken together, the control motive, overconfidence, and the false consensus bias suggest that our desire and perceived ability to influence other people should lead us not only to recognize, but also to overestimate, how much influence we have over others. However, in the next section we review two alternative areas of research that would lead us to make the opposite prediction - that we underestimate our influence over others.

\subsection{The Underestimation Hypothesis}

Despite the facts that (a) we have a lot of influence over others, and (b) we have a desire to feel influential and a tendency to see ourselves as influential, it is still unclear whether we truly recognize our influence. The notion that we may in fact underestimate our influence emanates from another classic area of psychology research concerned with how we make attributions for others' behaviors. Research on the fundamental attribution error (Jones \& Harris, 1967), or the correspondence bias [see Gilbert \& Malone (1995) for a comprehensive review], suggests that we do not recognize the extraordinary power of social influence when we attempt to explain the behavior of another person. We tend to attribute other people's behavior to stable, 
internal qualities (e.g., "He helped because he is nice") rather than situational factors (e.g., "He helped because someone asked him to do it").

More recent interpretations of the correspondence bias have suggested that we may be especially likely to discount face-saving concerns and social pressure as an explanation for others' behavior (e.g., Bohns \& Flynn, 2010; Bohns et al., 2011; Sabini, Sipemann, \& Stein, 2001; Van Boven, Loewenstein, \& Dunning, 2005). Indeed, social influence can frequently occur via self-conscious emotions, such as guilt and embarrassment. We feel guilty disobeying authority figures or failing to uphold our social obligations. Likewise, fear of embarrassment has been shown to be a potent driver of conformity in attitudes as well as behavior (Miller \& McFarland, 1987; Prentice \& Miller, 1993; Van Boven, 2000). Yet, notably, "hot" emotions like embarrassment are especially likely to be overlooked as a causal explanation for others' actions because we have a hard time recognizing the extent of others' discomfort (Bohns \& Flynn, 2010; Van Boven, Loewenstein, \& Dunning, 2005; Van Boven et al., 2013). As a result, people tend to underestimate the extent to which fear, embarrassment, and social pressure are likely to influence another person's decisions, feelings, or behavior.

This disconnect between what actually influences people's behavior and what we think influences people's behavior was examined in the aforementioned study by Nolan and colleagues (2008). In addition to collecting data on the kind of information that was most likely to influence actual conservation behavior — social norms versus information about environmental impact the researchers also surveyed a second community of California households about which information they believed would most influence their behavior. Respondents to this survey rated social norms (i.e., "Other people are doing it") as the least likely factor to influence their own behavior, instead favoring alternative explanations (e.g., "To protect the environment”). In other 
words, despite the fact that descriptive information about social norms was far superior in influencing actual energy conservation, people severely discounted the influence of social norms when predicting which kind of information would be most effective.

Milgram, as well, was curious about whether outside observers would recognize the amount of influence the experimenter had over participants in his obedience studies. Thus, as part of his original studies, Milgram had a group of individuals who were not involved with the studies estimate the proportion of participants they expected to succumb to this social pressure (i.e., the number of people they expected to continue administering shocks until they reached the highest voltage). These outside observers greatly underestimated compliance, predicting that $.125 \%$ of participants would comply in contrast to the $65 \%$ who actually complied (Milgram, 1963). Other researchers have reported higher estimates, such as the $38.9 \%$ reported by Blass (1999), yet even these outside observers' estimates are still much lower than participants' actual level of compliance. Thus, as far back as Milgram's classic obedience studies, we have known that outside observers discount the influence of social pressure on other people's behavior.

Over the years, researchers have focused more of their attention on these outside observers, trying to understand why they are unable to fully appreciate the power of these and other situations (Ross, 1977; Sabini, Siepmann, \& Stein, 2001). In contrast, we focus on the expectations of the influence agents themselves (e.g., the experimenters in Milgram's studies, the Anna Wintours of the world, and any member of a social organization), and we pose the following question: Given our desire to feel influential and our tendency to overestimate our abilities in so many domains, would we make the same attribution errors made by neutral observers and underestimate the social pressure we ourselves impart on others?

\subsection{Empirical Support for the Underestimation Hypothesis}


The few studies that have tested these two hypotheses directly suggest that we underestimate our influence over others when predicting and interpreting their behavior. A pair of studies by Gilbert and Jones (1986), for example, found that even when people elicited an attitude from someone explicitly, they still accepted the stated attitude as the person's own. The researchers had participants interrogate a "respondent" by asking questions that could be answered in either a politically liberal or conservative manner (e.g., "What do you think of the legalization of marijuana?"). As it turns out, the interrogators controlled how the respondents would answer each question. Specifically, the respondents had a sheet of paper with two experimenter-generated answers written on it: one was politically liberal and one was politically conservative. The interrogators would ask a question and then press a button that signaled to the respondent the exact answer (liberal or conservative) to read from their response sheet. Even though they were in fact prompting the respondents' answers, the interrogators were just as likely as outside observers to interpret the answers as indicative of the respondents' actual opinions. When the respondents gave a higher proportion of liberal responses, the interrogators rated them as more liberal, and when they gave a higher proportion of conservative responses, they rated them as more conservative, despite the fact that they determined the proportion of liberal or conservative answers provided by respondents.

More recently, Flynn and Lake (Bohns) (2008) found that people underestimate their influence over others in help-seeking (see also Bohns et al., 2011; Flynn \& Bohns, 2012;

Newark, Flynn, \& Bohns, in press). In these studies, participants solicited a number of different requests from passersby (e.g., asking people for the use of their cell phones, recruiting people to fill out questionnaires, and soliciting donations for a charity). Before making these requests, participants were asked to estimate how many people they would have to approach in order to 
get someone to say "yes." Across every type of request, participants greatly overestimated the number of people they would have to ask to get someone to agree with their help request; people were far more likely - in fact, twice as likely - to say "yes" than participants expected. Although the participants in these studies could get assistance fairly easily, the power they had to do soto influence others' behavior-was lost on them.

Bohns, Roghanizad, and Xu (2014) replicated these findings using unethical requests rather than prosocial requests. In one study, "primary participants" asked other "secondary participants" to vandalize a library book; in other words, these secondary participants acted as intermediaries (Paharia et al. 2009) to the primary participants' unethical deeds. Before making these unethical requests, primary participants predicted how likely secondary participants would be to agree to engage in the unethical act and how comfortable they would feel saying "no." As in the studies by Flynn and Lake (2008), participants greatly underestimated how likely others would be to agree to engage in the act because they overestimated how comfortable secondary participants would feel saying "no." Although many secondary participants protested, stating that they were uncomfortable performing the act, they felt as if they could not say "no" and therefore agreed to deface the book despite their hesitations.

In addition to the handful of studies that have tested this hypothesis directly, indirect support also exists. Such support comes from research on the self-fulfilling prophecy (Merton, 1957), which refers to a situation in which expectations for how an individual will behave ultimately lead that individual to behave in the expected manner. These expectations often come from external influence agents - another person (or persons) whose expectations for that individual ultimately determine the individual's behavior. The classic demonstration of the selffulfilling prophecy is Rosenthal and Jacobson (1968)'s study of how teachers' expectations can 
affect student performance. When teachers were told that a set of randomly selected students was gifted, the students showed a significant increase in their academic performance at the end of the study, presumably due in part to the teachers' extra attention and support. Eden (1990) has extended these principles to the workplace and demonstrated the extraordinary power of supervisors' expectations to affect subordinates' productivity (see also Eden \& Shani, 1982).

In many cases, the person whose expectations are influencing the target's behavior is the same person who is evaluating the target. In one study, Ward, Zanna, \& Cooper (1974) found that interviewers treated black and white interviewees differently - interviewers sat farther away from black candidates, spent less time with black candidates, and exhibited more speech errors (stutters, sentence changes, incoherent sounds). As a result, black candidates don't have as much time with the interviewer and the time they did have felt awkward; consequently, they performed more poorly than white candidates. Although the interviewers may have been primarily responsible for the candidates' success or failure based on their inconsistent handling of the interview, the end result is that black candidates were less likely to be hired. Like the teachers in Rosenthal and Jacobson's (1968) study, the interviewers may be unlikely to attribute the success or failure of the interviewee to their treatment of that individual; that is, they fail to consider the influence they may have had in eliciting a self-fulfilling pattern of poor performance.

In sum, the findings reported by Gilbert and Jones (1986), Flynn and Lake (2008), and self-fulfilling prophecy scholars appear to contradict research on the illusion of control and overestimation, at least when it comes to estimating one's own influence. Participants in each of the former studies underestimated how much control they had in situations involving their personal influence over others.

\section{Underestimating Our Influence Over Others at Work}


What are the implications of underestimating one's influence in the workplace? In the case of managing human resources, many hiring, promotion, and turnover decisions are based on the attributions managers make for an individual's past or future performance (Lord \& Smith, 1983). We hire a job candidate based on what he chose to talk about in the interview, not the kinds of questions we posed during the interview. We promote an employee because we attribute her excellent performance to her abilities, rather than to our own supervisory skills. We change jobs because we believe our boss has been too "hands off," despite the possibility that we may have been loath to accept his support. In each case, our judgment partly depends on whether we think the outcome in question is the result of our personal influence or the target's own doing.

Previous research has explored how such attributions impact an individual employee's judgments and decisions. For example, performance appraisals involve assessing whether successes and failures should be attributed to a particular employee as opposed to the situation he or she inherited (Feldman, 1981; Green \& Mitchell, 1979), reactions to organizational wrongdoing may be affected by whether those culpable "went rogue" or were merely following company norms (Gailey \& Lee, 2005), and responses to both favorable and unfavorable stock performance involve identifying the extent to which the CEO was responsible for an organization's performance or if it was simply beyond their control (Salancik \& Meindl, 1984). In each of these situations, judgments and decisions are based on whether causality is attributed to the situation (i.e., the extenuating circumstances) or the target individual.

However, in many instances we are the situation to which culpability can be assigned. That is, the "extenuating circumstances" are in fact behaviors we have enacted (e.g., our own managerial style, decisions we made, our failure to speak up against others' actions). In such instances, rather than deciding whether causality is attributable to the target individual or the 
situation, we must instead decide whether causality is attributable to the target individual or

ourselves. If people indeed underestimate their own influence, we would attribute greater culpability for events (good or bad) to others, while simultaneously shirking our own responsibility. Such a tendency has important organizational implications.

\subsection{Organizational Implications: Three Examples}

Underestimating one's influence has important implications for a wide variety of organizational processes, all of which cannot be discussed here. To exemplify the applications of this bias for the workplace, we apply it to three representative domains: managing organizational change, conducting performance appraisals, and engaging in whistle-blowing.

\subsubsection{Organizational Change}

The process of organizational change requires change agents to "unfreeze" their employees and colleagues, gain access to key resources, and persuade others to follow a new direction (Furst \& Cable, 2008; Hannan \& Freeman, 1984; Lewin, 1951). Battilana and Casciaro (2012) state that "[c]hange implementation within an organization can thus be conceptualized as an exercise in social influence, defined as the alteration of an attitude or behavior by one actor in response to another actor's actions (Marsden \& Friedkin, 1993)." Nevertheless, people tend to be highly resistant to change, so getting them to go along with change efforts can be a formidable social influence task requiring an extraordinary amount of effort (Kanter, 1983; Reger, Gustafson, Demarie, \& Mullane, 1994; Van de Ven, 1986).

To get employees onboard with their vision, leaders are taught to manage change by allocating sufficient time for the change to take place (Sirkin, Keenan, \& Jackson, 2005) and introducing attractive organizational inducements (Shin, Taylor, \& Seo, 2012). However, in 
addition to these practical and logistical recommendations, leaders managing change also must work on "winning people's hearts and minds" by gaining employees' commitment (Sirkin, Keenan, \& Jackson, 2005) and helping them to adjust (Shin, Taylor, \& Seo, 2012).

This latter aspect of change management requires persuasion and influence. According to Dutton et al. (2001), this process can be considered akin to "selling" ideas that are in turn "bought" by others. As part of this process, people develop their own lay theories about how effective they are likely to be at getting their points across to others using a variety of techniques. If an individual does not believe she will be effective at selling her ideas to her colleagues, she is not likely to engage in a change effort. For example, Ashford and colleagues (1998) found that the perceived probability that the organization will be receptive to a particular change effort - in their study, the change effort involved gender equality - determined how willing managers were to invest time in selling the issue.

Lay theories of how effective one is likely to be at effectively shaping change are therefore highly relevant to change efforts. If individuals underestimate their ability to influence others, as research suggests, they will likely fail to devote enough time, effort, and preparation into convincing others of their plans (see also Dermer \& Lucas, 1986). They may not recognize the effectiveness of influence strategies, relying instead on change solutions, such as incentives, that are unrelated to their own persuasive skills. Thus, in addition to emphasizing the importance of change-management strategies that are external to change agents' own persuasive abilities, it may be useful to challenge change agents' a priori assumptions about their potential influence and encourage them to devote more time to making persuasive appeals.

\subsubsection{Performance Appraisal}

As noted earlier, we make decisions regarding whether to hire, promote, and terminate 
employees based on our appraisals of their performance. However, the process of making such appraisals is complicated and imperfect, based on incomplete information, and prone to a number of attribution biases (Feldman, 1981). One such bias is the extent to which we attribute an employee's performance to his or her own stable, internal characteristics, such as conscientiousness and agreeableness (Barrick \& Mount, 1991) as opposed to our own management skills. A boss who underestimates his influence, as research suggests people are likely to do, would in turn underestimate his role in his employees' performance. He may therefore be too quick to reassign responsibilities or part ways with a weak performer, rather than adjust his own management style. He may also fail to recognize an underperforming employee's potential if only the employee were provided with more extensive training. Further, a manager may misdiagnose the kinds of incentives that will be most effective in motivating an employee's performance: he may use external incentives, like punishments and rewards, rather than first trying persuasion and subtle social pressure (e.g., "We are all counting on you to get this right").

Such a tendency complements and extends Carol Dweck's work on incremental versus entity theories of intelligence. According to Dweck and colleagues (e.g., Dweck, Chiu, \& Hong, 1995), entity theorists believe that intelligence is fixed and would therefore attribute a struggling employee's failures to a stable, internal quality of the employee, e.g., "He isn't cut out for the job." Conversely, incremental theorists believe that intelligence is malleable and would therefore attribute a struggling employee's failures to a lack of effort, e.g., "He isn’t working hard enough." Yet, implicit theories of performance do not address individual's theories about how interpersonal influences may effectively motivate or demotivate an individual's performance. That is, while an incremental theorist believes that someone can improve with effort, she does not necessarily believe that she can help that person to learn. Thus, even 
incremental theorists may underestimate their own role in motivating a struggling employee to increase his or her efforts.

\subsubsection{Whistle-Blowing}

Whistle-blowers are defined as members of organizations who "disclose illegal, immoral, or illegitimate practices under the control of their employer to persons or organizations who may be able to effect action" (Near \& Miceli, 1985, p.6). In other words, whistle-blowers are individuals who choose to disclose unethical organizational practices because they think they can influence those practices. According to Dozier and Miceli (1985), "whistle-blowers can call attention to organizational problems; as a result, solutions may follow." Although one might think of whistle-blowers as people with a stronger moral identity than most, the evidence for this assumption is quite mixed; rather, the most consistent predictor of whistle-blowing is a sense of formal or informal responsibility (Vadera, Aguilera, \& Caza, 2009). People who think of reporting organizational misdeeds as their responsibility are more likely to believe that their attempts to do so will be effective at motivating change (Trevino \& Victor, 1992; Victor, Trevino, \& Shapiro, 1993).

What makes someone likely to believe that it is his or her responsibility to report organizational wrongdoing? According to Miceli, Near, \& Schwenk (1991), such a belief is in large part determined by one's perceptions of one's own power and influence. As Miceli, Near, \& Dworkin (2008) state, "those who hold important or credible positions - such as Sherron Watkins of Enron - may feel that they are obliged to act, that they can get someone to listen, and that they will escape negative consequences such as retaliation" (p. 44). Thus, the question of whether individuals over- or underestimate their own influence - their ability to "get someone to listen" - is an important determinant of whether or not they choose to blow the whistle on 
corporate wrong-doing.

In particular, if whistle-blowers choose to disclose unethical organizational practices because they think they can influence those practices, underestimating their influence will lead to fewer whistle-blowing attempts. Employees who underestimate their influence would likely fail to recognize numerous opportunities to affect organizational policies and decisions from within the organization because they assume their protestations will not carry much weight. Doubting their ability to affect change, whistle-blowers may go to external resources as a first step, instead of approaching managers and colleagues directly, or they may keep silent altogether.

In this section, we have reviewed some of the ways in which underestimating one's influence over others can have important practical implications for organizations. Bosses who do not appreciate their sway over their employees may abandon all hope of improving a poor performing employee's performance. Individual employees who do not recognize the extent of their power may be reluctant to champion important change efforts, and may stay silent in the face of organizational wrongdoing. In short, many valuable endeavors that could be accomplished in the workplace may be abandoned before they are even begun because of doubts about one's influence.

\section{Reconciling the Underestimation and Overestimation Hypotheses}

If people tend to underestimate their influence over others, how can we reconcile this tendency with their desire to feel in control of their environment and their propensity to be overconfident in other domains? Why doesn't the control motive, which leads individuals to overestimate their control over outcomes as diverse as lottery tickets, sports outcomes, and getting in car accidents as passengers similarly lead them to attribute more responsibility to themselves for others' behavior? In this section, we attempt to reconcile the former 
overestimation hypothesis with the contradictory evidence we have presented in support of the underestimation hypothesis and propose five moderators that, when present, may reverse or attenuate the underestimation effect.

\subsection{Theoretical Reconciliations of the Two Hypotheses}

One theoretical explanation for why we often don't find overestimation in the domain of interpersonal influence may involve the magnitude of control we actually have over other people in interpersonal interactions. We often have considerable influence over others' thoughts and behaviors. But according to recent research, in situations in which people have high levels of actual control, they may in fact underestimate the amount of control they have (Gino, Sharek, \& Moore, 2011). In a series of experiments, participants were given a probabilistically high degree of control over an annoying background timer that turned their computer screens black while they were working on a task. However, participants' estimates of control over the timer were much lower than their actual level of control (Gino, Sharek, \& Moore, 2011). The researchers explained their findings by arguing that people's judgments are generally miscalibrated in ways that lead them to systematically overestimate ability, performance, or control in situations where ability, performance, or control are in fact very low, but underestimate ability, performance, or control in situations in which they are actually quite high. Similar reasoning can explain the findings by Gilbert and Jones (1986) and Flynn and Lake (2008). That is, people may underestimate their own influence in interpersonal interactions because the degree of control people actually have in this domain is extremely high, not because of any special qualities unique to social interactions.

Alternatively, there may be an inherently social explanation for why we don't find overestimation in the domain of interpersonal influence that reflects different aspects of the 
attribution process. According to Hamilton (1980), there is a distinction between causal attributions and attributions of responsibility. The former type of attribution seeks to attribute causality for an event. That is, attributions of causality seek to answer the question, "Did the behavior I engaged in lead to the behavior someone else subsequently engaged in?" The latter seeks to attribute responsibility for an event. That is, attributions of responsibility attempt instead to answer the question, "Could the individual have done otherwise?" In other words, a preceding behavior by one person may indeed "pull for" a subsequent behavior by another person, but if the latter person had a choice to do something else, he or she is ultimately responsible for his or her behavior.

The obvious difference between lottery tickets and people is that people have intentionality (see also Heider, 1958; Heider \& Simmel, 1944; Wegner, Sparrow \& Winerman, 2004). When we try to determine whether or not we influenced a physical outcome (a dice roll, the changing of a light), we need only answer Hamilton's first question about causality, i.e., "Did the behavior I engaged in lead to the outcome?” Thompson, Armstrong, \& Thomas (1998) make a similar argument when describing the control heuristic people use to determine whether or not they have influenced a given event. They argue that in making this determination, people use two pieces of information: the contingency between one's behavior and an outcome, and one's own intention to elicit a particular outcome. So, for example, if I engage in a behavior that elicits an outcome and I wanted the outcome to occur, I am likely to believe that I influenced the outcome.

On the other hand, when determining whether or not I influenced another person's behavior, considering contingency and my own intention alone cannot provide me with a satisfactory answer. To understand another person's behavior, I also need to consider the other 
person's intentions and answer Hamilton's second question regarding responsibility. Even if my own behavior precedes another person's corresponding behavior, I still need to determine whether or not the person could have done otherwise. If I believe that he or she could have done something else in a given situation, I will underestimate the extent to which I was responsible for his or her behavior, even if I acknowledge that I may have caused his or her behavior. That is, my behavior may have "pulled for" his or her behavior, but he or she ultimately made the decision to comply with my request or follow my behavior. For example, a boss may ask an employee to work over the weekend, prompting, and therefore causing, the employee's subsequent behavior of working over the weekend. But the employee himself is ultimately responsible for his behavior by intentionally choosing to follow his boss's request. In sum, according to Hamilton's theory, individuals are likely to underestimate their interpersonal influence as a result of miscalibrations in attributions of responsibility, attributions that do not apply to the typical skills tasks used in demonstrations of illusory control and overconfidence.

\subsection{Possible Moderating Factors}

Despite empirical support for the underestimation hypothesis, and despite the aforementioned theoretical explanations for why underestimation would be more likely to occur than overestimation in the domain of interpersonal influence, there will inevitably be some situations in which people do in fact overestimate their influence over others. It is easy to bring to mind examples of CEOs and managers who think they have greater control over their companies and employees than they actually do. How can our theory account for these instances? We propose five moderating factors that may reverse the underestimation effect: (1) comparative judgments, (2) objectification or dehumanization of the influence target, (3) the degree of influence an individual actually has in a given situation, (4) the means of influence, and (5) culture. We 
review each of these proposed moderating factors below.

\subsubsection{Comparative Judgments}

Our theoretical argument for the underestimation of influence, and the empirical data we have presented in support of this bias, is based on a comparison between an individual's expectations of how influential she will be in a given situation and how influential she actually is in that situation. We have argued that people are constrained by their own egocentric perspectives and are therefore unable to fully appreciate the perspectives of the people they are trying to influence. They fail to consider the self-conscious feelings of guilt and embarrassment that often lead people to go along with another person's request, and consequently underestimate their own capacity to get others to do what they want.

However, another way to measure an individual's expectations of his or her own influence would be to ask the individual how influential he or she is compared to other people. For example, in a typical illusory superiority paradigm (see Kruger \& Dunning, 1999), participants are asked to rate themselves on how intelligent, attractive, or moral they are compared to the average person. People generally rate themselves as higher than the average person on each of these dimensions resulting in the "Lake Wobegon Effect," or the finding that the average person thinks he is more attractive, intelligent, and moral than the average person.

The mechanism behind these illusory superiority findings and the mechanism underlying the findings we have described in support of the underestimation of influence are quite different. In illusory superiority studies, participants simply compare themselves to other people; there is no perspective-taking component to such studies. However, in the studies we described in support of the underestimation of influence, participants' expectations were compared to an actual reality - a reality that can only be accurately predicted by effectively taking the 
perspective of the influence target. If these participants were to instead compare their perceived influence abilities to the influence abilities of the average person, we would expect to find a reversal bias of the underestimation bias. We would expect to find, like Kruger and Dunning have found in other domains, that influencers overestimate their abilities compared to the average person.

To put this moderator into an organizational context, if we were to ask a manager, Steve, how effective he expects to be at turning around a poor-performing employee, Steve may underestimate his influence over the employee. He may claim that the employee has no work ethic or is difficult to train, and hence underestimate the role he could play in motivating the employee to improve. However, if we were to ask Steve how effective he would be at turning around a poor performing employee compared to the average manager, he would likely claim to be better able to do so, hence overestimating his influence.

\subsubsection{Objectification or Dehumanization of the Influence Target}

A second moderator that may lead to a reversal of the underestimation effect is the objectification or dehumanization of the influence target, or the tendency to view an influence target as more similar to a physical thing than a person. We have argued that individuals underestimate their influence because they overestimate the extent to which other people will exercise their own intentionality, in other words, the extent to which people will do what they want to do, rather than yielding to social pressure. In response to a specific request, requesters often assume the targets will ultimately exercise their own desires, saying "no" if they are uncomfortable with a specific course of action. Of course, as we have seen, this is often not the case - people frequently engage in requested behaviors even when they feel uncomfortable doing so. 
However, such a bias is likely to emerge only when a potential influencer acknowledges the fact that another person actually has intentionality (i.e., the person has a will of her own that she will exercise when she so desires). As Gray and colleagues (2011) have found, objectification reduces perceptions of agency. Individuals viewed as bodies devoid of minds are considered by others to be less responsible for their actions. As a result, when individuals are objectified - when they are seen as more similar to lottery tickets than intentional beings - we would no longer expect to find an underestimation of influence. Rather, influencers who objectify the individuals they are attempting to influence would likely overestimate their control. They would no longer ask Hamilton's second question about responsibility (“Could the individual have chosen to do otherwise"), because there is relatively little consideration of the target individual's choice in the matter.

According to Haslam (2006), dehumanization occurs when we equate men to machines or animals. For this reason, managers who have a more Taylorist view of their subordinates, seeing them as special-purpose machines that are programmed to perform designated tasks (Montague \& Matson, 1983; Taylor, 1947), are likely to overestimate their influence. They see their potential influence, at least downward influence, as substantial because others are unlikely to resist their requests. A similar reversal may also emerge from the objectification of specific social groups. For example, employees may objectify female colleagues as subservient, which would lead them to overestimate their control over female co-workers or a female boss (see Gruenfeld, et al. 2008). Further, employees may objectify and dehumanize members of various races and ethnicities, and hence overestimate their control over colleagues they consider outgroup members (Bandura, Underwood \& Fromson, 1975). In essence, the more an individual objectifies a target of influence, and therefore fails to appreciate the target's intentionality, the 
more likely that individual is to overestimate, rather than underestimate, his or her own influence.

\subsubsection{The Influencer's Actual Degree of Influence}

Our argument for the underestimation of influence is based on the premise that individuals do indeed have substantial influence over their colleagues. As noted by Gino, Sharek, and Moore (2011), the underestimation of control is likely to occur in circumstances in which an individual has a significant degree of control. However, in situations where individuals have very little control, the overestimation of control is likely to occur. A similar moderation prediction could be made for the underestimation of social influence.

While evidence abounds that social pressure is a powerful form of influence, it is not the only source of influence a target may confront. A target of influence may have other concerns that pull for behaviors contrary to the behaviors desired by the influencer. For example, concerns with autonomy or competence (Deci \& Ryan, 1987) may overshadow an individual's social concerns, leading her to reject a colleague's request to admit fault for a mistake. Alternatively, a target may be pulled in opposite directions, such as when two bosses give different directions or a boss and a colleague offer conflicting advice. In situations where there are a multitude of potential influences weighing on a single target, a single influencer may not have a great deal of actual influence.

In such cases, we may see a reversal of the underestimation effect, such that influencers overestimate their influence over the target. For instance, an employee's boss may request a specific format for a presentation the employee is drafting. However, the same employee's colleague may offer some suggestions that run contrary to her boss's desires. In this case, the employee's colleague likely does not have much influence over the employee's behavior, yet he 
or she may be inclined to believe that such influence exists. In this case the underestimation effect is likely to reverse.

\subsubsection{Means of Influence}

We have argued that people tend to underestimate the degree of influence they have over others via social mechanisms, such as conformity pressures and social norms, which in turn evoke emotions such as guilt, embarrassment, and shame that frequently arise when one attempts to subvert social norms and say "no." Until now we have not considered other forms of influence, namely, influence via economic means, such as rewards and punishments. Research suggests that when judging the degree of influence we have over others through these more instrumental means, we may in fact overestimate rather than underestimate our own influence.

A classic study by Strickland (1958) reveals people's tendency to attribute others' behaviors to instrumental influence. Participants were put in charge of supervising two "subordinates" in a task as part of a study on supervisory practices. All participants were instructed to provide one subordinate with a higher degree of supervision than the other, which essentially consisted of meting out more fines and incentives for one of the subordinates than the other. Although participants were told that both subordinates performed equally well on the task, and although the subordinates were randomly assigned to supervisory condition, supervisors reported that the subordinate who received less supervision was more dependable and more trustworthy than the other. In other words, supervisors attributed the highly supervised subordinate's behavior to external incentives rather than to his or her internal work ethic.

Work by Miller and Ratner (1998) further demonstrates people's tendency to overestimate the influence of economic incentives on others' behavior. In their classic blood donation study, participants predicted that their fellow classmates would be considerably more 
likely to donate blood if there was an economic incentive to do so. However, actual blood donation rates increased only slightly when an economic incentive was offered.

Taken together, these studies suggest that while people may underestimate the role of social pressure in influencing others' behavior, they may conversely overestimate the role of instrumental or economic influences such as rewards and punishments. Two classic studies by Kipnis et al. (1976) further suggest that this distinction is also likely to apply to judgments of one's own influence. Kipnis and colleagues surveyed a sample of married couples and a sample of housewives who employed housemaids. In both studies, participants were asked about the kinds of influence tactics they typically used, either with their spouses or with their employees. These influence tactics ranged from what the researchers refer to as "strong" tactics, which include economic incentives, for example, "use rewards that make my spouse happy in exchange for agreement" or "offer incentives for improvement," to "weak" tactics, such as "appeal to the person's love and affection for me." When participants reported using stronger, economic tactics, they tended to attribute the other party's subsequent behavior, for example, their spouse's willingness to compromise, or their maid's performance, to the economic incentives they offered. However, when they reported using weaker, social tactics, they tended to attribute the other party's behavior to his or her own volition, hence underestimating their own influence over the other person's behavior.

This distinction between social and economic influence has important implications for other potential moderators of the underestimation effect, for example, power differentials. By definition, the influence possessed by people in power is economic - power is defined as asymmetric control over valued resources (Magee \& Galinsky, 2008). As a result, people with power may be more likely to overestimate than underestimate their own influence - not because 
they have more influence, but because their means of influence is economic rather than social. This may explain why some CEOs seem to believe they can control anyone they want.

In sum, the means of influence - economic or social - are likely to be an important moderator determining whether overestimation or underestimation of influence occurs.

Specifically, a supervisor who needs her subordinates to stay late one evening may underestimate the efficacy of invoking feelings of guilt in such a situation (a social mechanism), but overestimate the efficacy of offering a small bonus (an economic incentive).

\subsubsection{Culture}

The tendency to discount social pressure and norms as explanations for other people's behavior may be culturally bound and especially prevalent in relatively individualistic cultures, like the United States. An important characteristic of individualistic cultures is an assumption that each individual is uniquely responsible for looking after his own personal needs and desires (Markus \& Kitayama, 1991; Triandis, 1995). Members of individualistic cultures are believed to act largely of their own volition - doing something only if it is consistent with their own personal wishes - rather than out of a sense of obligation or social pressure. Conversely, a central tenet of collectivistic cultures is an assumption of interdependence (Markus \& Kitayama, 1991). In collectivistic cultures, the needs and goals of the group will presumably usurp individual desires and personal interests. As a result, members of collectivistic cultures may be more aware of how social norms shape their own and others' behavior.

Cross-cultural research supports this proposition. The correspondence bias tends to be attenuated in collectivistic cultures like Japan (Choi, Nisbett, \& Norenzayan, 1999; Masuda \& Kitayama, 2004;). Further, when Study 1 from Flynn \& Lake (Bohns) (2008) was replicated in a relatively individualistic culture (i.e., the United States) and a relatively collectivistic culture 
(i.e., China), the predictions of compliance made by Chinese help-seekers were more accurate than were those made by the American participants (Bohns et al., 2011). Although the underestimation effect was still present in both groups, it was attenuated in the more collectivistic culture.

Mazar and Aggarwal (2011) even identified a dark side of this cultural difference in attributing responsibility for individual behavior to the individual versus the group. They found that collectivism was related to an increased propensity to bribe in a cross-national correlational study, and the relationship between collectivism and bribery was mediated by individuals' sense of responsibility for their actions. Individuals who rated higher in collectivism were more likely to attribute unethical acts to the social context, rather than to their own personal will.

In general, it seems that more individualistic cultures put a premium on personal control when determining who is ultimately responsible for a decision or behavior, whereas more collectivistic cultures prioritize the role of social influence, or collective control (see also Yamaguchi, Gelfand, Ohashi, \& Zemba, 2005). All of this research suggests that the underestimation effect may be attenuated in collectivistic cultures.

In sum, we have tried to answer the question of why, if people tend to overestimate the control they have over so many aspects of their lives, this tendency frequently does not generalize to the interpersonal domain. We have provided two potential theoretical explanations for this discrepancy: (1) The sheer magnitude of our influence over others may impair our judgments. (2) We may believe that individuals ultimately have responsibility for their own behavior (i.e., regardless of any social pressure, someone can always choose to do otherwise). In addition, we have attempted to address the fact that despite the robustness of the underestimation of influence effect, there will undoubtedly be situations in which the opposite effect may occur, 
leading someone to overestimate their influence over others. To address this likelihood, we have proposed five possible moderators (comparative judgments, the objectification or dehumanization of an influence target, the actual degree of influence any one influencer has, the means of influence, and culture) that can account for instances in which the underestimation of influence effect may be reversed or attenuated.

\section{Discussion}

We began this article by asking whether individuals recognize their own influence over others in the workplace and reviewing two competing predictions: overestimation and underestimation. We provided evidence supporting the underestimation hypothesis and discussed some practical implications that underestimating one's influence may have for organizations, specifically with respect to performance appraisal, managing organizational change, and whistle-blowing (of course there may be many more). We also provided a potential reconciliation of the two hypotheses, and we proposed five moderators that may cause this bias to reverse in certain situations, namely, comparative judgments, the objectification or dehumanization of an influence target, an individual's actual degree of influence in a situation, the means of influence, and culture. In this final section, we propose some practical solutions to address this tendency as well as offering some suggestions for future research.

\subsection{Practical Solutions}

We can readily see how this bias can negatively affect organizational life. Employees who tend to underestimate their influence over others will be reluctant to spearhead new initiatives in the workplace, unwilling to admit their role in their subordinates' performance failures, and less likely to speak up in the face of organizational wrongdoing. They may also be too quick to rely on external incentives, such as rewards and punishments, to manage employee 
performance and organizational change, rather than trusting in their own powers to persuade and motivate. In short, this bias seems debilitating, but can it be corrected?

Although cognitive biases are difficult to override, research offers some hope that we can make people aware of their influence over others. Egocentric biases are generally thought to be the result of unconscious, automatic processes (Epley \& Caruso, 2004); consequently, such biases can sometimes be minimized through conscious consideration of others' perspectives and circumstances (Caruso, Epley, \& Bazerman, 2006). Getting bosses, employees, and coworkers to deliberately consider the perspective of others within their realm of influence (e.g., when completing a performance appraisal a manager might be asked to describe their own role in causing the employee's failures or successes), may be one means of reducing this bias. As Emily Pronin (2008) has suggested, simply making people aware of these biases, whether they like it or not, may help to reduce them.

Further, biases caused by automatic cognitive processes are more likely to occur when people are under stress or cognitive load (e.g., Kruger, 1999; Sherman et al., 1998). In general, organizational change efforts tend to be stressful experiences. Such stress may lead people to develop less optimistic views of whether such change can be accomplished (i.e., whether they can be successful in persuading others to accept such change). Noting this challenge, it may be worthwhile for organizations to find ways to lighten the anxiety that often accompanies change initiatives. Doing so may embolden managers to take more meaningful and deliberate action toward converting the skeptics, naysayers, and intransigent.

\subsection{Suggestions for Future Research}

Although there is much research on what makes people influential, there is relatively little research on how aware individuals are of the influence they have over others in the 
workplace and the impact of this awareness (or lack thereof). If we do not recognize the influence we have over others, will we be more likely to make an insensitive remark or immoral demand? Will we avoid making a constructive suggestion because we assume it won't hold any weight? In an era where auditing agencies communicate openly with the companies they audit (Morgenson, 2008) and the social dynamics of trading rooms can foster shockingly unethical risky shifts (McLean \& Elkind, 2003), the question of whether we as individuals understand the extent to which we contribute to a social norm, a collective value system, or simply another individual's assessment of the appropriate course of action in a given situation has important practical implications.

Rather than explore how collective value systems and social norms are established, we should also explore the conditions under which individuals are aware that they are contributing to collective value systems and social norms. In addition to researching how individuals judge themselves and others for committing unethical acts under pressure from external forces, we should also research how the individuals exerting the external pressure view the actions of those they are pressuring. For example, Paharia and colleagues (2009) found that people judged individuals who ordered someone else (an intermediary) to commit an unethical act to be less unethical than individuals who committed an unethical act themselves. In these studies, outside observers assumed the intermediary was acting of his or her own free will, despite the fact that the researchers made it clear the intermediary was simply an instrument of the primary agent. It may be worthwhile for future research to contrast the perspectives of these outside observers to the primary agents. Do the individuals who ordered the act draw similar conclusions? And what consequences does this have for the primary agents' own actions?

\section{Conclusion}


Although people tend to overestimate the control they have over many aspects of their lives, this tendency frequently does not generalize to the interpersonal domain. We have argued that when it comes to other people, we tend to lack confidence in our ability to get them to do what we want. Further, we may not realize the extent to which we inadvertently influence someone to do something we do not want him or her to do. The sheer magnitude of our influence over others may impair our judgments of others' intentionality. Or, we may believe that individuals ultimately have responsibility for their own behavior (i.e., regardless of any social pressure, someone can always choose to do otherwise). Yet, the literature on social influence and conformity suggests that choosing to do otherwise is far easier said than done. The underestimation bias can have important implications for organizations, many of which are negative. But illuminating the actual influence employees have over one another may, we hope, embolden them to wield such influence in productive ways. 


\section{References}

Abramson, L. Y., Seligman, M. E. P., \& Teasdale, J. D. (1978). Learned helplessness in humans: Critique and reformulation. Journal of Abnormal Psychology, 87, 49-74.

Ackerman, R. \& DeRubeis, R. J. (1991). Is depressive realism real? Clinical Psychology Review, $11,565-584$.

Adams, G. A., King, L. A. \& King, D. W. (1996). Relationships of job and family involvement, family social support, and work: Family conflict with job and life satisfaction. Journal of Applied Psychology, 81, 411-420.

Alicke M. D. \& Govorun, O. (2005). The better-than-average effect. In M. Alicke, D. Dunning and J. Krueger (eds) The Self in Social Judgment. New York: Psychology Press, 85-106.

Alloy, L. B. \& Abramson, L. Y. (1979). Judgment of contingency in depressed and nondepressed students: Sadder but wiser? Journal of Experimental Psychology: General, $110,436-447$.

Alloy, L. B., Abramson, L. Y., \& Viscusi, D. (1981). Induced mood and the illusion of control. Journal of Personality and Social Psychology, 41, 1129-1140.

Alvarez, R. (1968). Informal reactions to deviance in simulated work organizations: A laboratory experiment. American Sociological Review, 895-912.

Ansari, M. A., \& Kapoor, A. (1987). Organizational context and upward influence tactics. Organizational Behavior and Human Decision Processes, 40(1), 39-49.

Asch, S. E. (1951). Effects of group pressure upon the modification and distortion of judgment. In H. Guetzkow (ed.) Groups, leadership and men. Pittsburgh, PA: Carnegie Press.

Asch, S. (1956). Studies of independence and conformity: A minority of one against a 
unanimous majority. Psychological Monographs, 70, 1-70.

Ashford ,B. \& Anand V. 2003. The normalization of corruption in organizations. In R Kramer, B Staw (Eds.), Research in Organizational Behavior, Vol. 25: 1-52.

Ashford, S. J., Rothbard, N. P., Piderit, S. K., \& Dutton, J. E. (1998). Out on a limb: The role of context and impression management in selling gender-equity issues. Administrative Science Quarterly, 23-57.

Avolio, B. J. (2007). Promoting more integrative strategies for leadership theory-building. American Psychologist, 62(1), 25.

Bandura, A., \& McClelland, D. C. (1977). Social learning theory.

Bandura, A., Underwood, B., \& Fromson, M. E. (1975). Disinhibition of aggression through diffusion of responsibility and dehumanization of victims. Journal of Research in Personality, 9, 253-269.

Barrick, M. R., \& Mount, M. K. (1991). The big five personality dimensions and job performance: a meta- analysis. Personnel psychology, 44(1), 1-26.

Battilana, J., \& Casciaro, T. (2012). Change Agents, Networks, and Institutions: A Contingency Theory of Organizational Change. Academy of Management Journal, 55(2), 381-398.

Beu, D. S., \& Buckley, M. R. (2004). This is war: How the politically astute achieve crimes of obedience through the use of moral disengagement. The Leadership Quarterly, 15(4), $551-568$.

Blanchard, M. (1993). Managing for wellness. Executive Excellence, 8-9.

Blass, T. (1999). The Milgram paradigm after 35 years: Some things we now know about obedience to authority. Journal of Applied Social Psychology, 29, 955-978. 
Bohns, V. K., \& Flynn, F. J. (2010). "Why didn’t you just ask?" Underestimating the discomfort of help-seeking. Journal of Experimental Social Psychology, 46, 402-409.

Bohns, V. K., Handgraaf, M. J. J., Sun, J. M., Aaldering, H., Mao, C., \& Logg, J. (2011). Are social prediction errors universal? Predicting compliance with a direct request across cultures. Journal of Experimental Social Psychology, 47, 676-680.

Bohns, V. K., Roghanizad, M. M. \& Xu, A. (2014). Underestimating our influence over others' (un)ethical behaviors and decisions. Forthcoming in Personality and Social Psychology Bulletin.

Brief, A.P., Buttram, R.T., Dukerich, J.M. (2001). Collective corruption in the corporate world: toward a process model. In Groups at Work: Advances in Theory and Research, M. E. Turner (Ed.), pp. 471-99. Hillsdale, NJ: Erlbaum.

Brief, A.P., Buttram, R.T., Elliot, J.D., Reizenstein, R.M., McCline, R.L. 1995. Releasing the beast: a study of compliance with orders to use race as a selection criterion. Journal of Social Issues, 51,177-94.

Brief, A. P., Dietz, J., Cohen, R. R., Pugh, S. D., \& Vaslow, J. B. (2000). Just doing business: Modern racism and obedience to authority as explanations for employment discrimination. Organizational behavior and human decision processes, 81(1), 72-97.

Burger, J. M. (2009). Replicating Milgram: Would people still obey today? American Psychologist, 64, 1-11.

Cain, S. (2011). Quiet: The power of introverts in a world that can't stop talking. Crown.

Caruso, E. M., Epley, N., \& Bazerman, M. H. (2006). The good, the bad, and the ugly of perspective taking in groups (Vol. 8, pp. 201-224). Emerald Group Publishing Limited. Choi, I., Nisbett, R. E., \& Norenzayan, A. (1999). Causal attribution across cultures: Variation 
and universality. Psychological bulletin, 125(1), 47.

Cialdini, R. B., Reno, R. R. \& Kallgren, C. A. (1990). A focus theory of normative conduct: Recycling the concept of norms to reduce littering in public places. Journal of Personality and Social Psychology, 58, 1015-1026.

Cutler, R. (2009). The September Issue. United States: Roadside Attractions.

Darley, J.M., Messick, D.M., \& Tyler T.R. (Eds.) (2001). Social Influences on Ethical Behavior in Organizations. Mahwah, NJ/London: Erlbaum.

Deci, E. L., \& Ryan, R. M. (1987). The support of autonomy and the control of behavior. Journal of personality and social psychology, 53(6), 1024-1037.

De Cremer, D., \& Tenbrunsel, A. E. (2012). Behavioral business ethics: Ideas on an emerging field. Routledge.

Dermer, J. D., \& LucAS, R. G. (1986). The illusion of managerial control. Accounting, Organizations and Society, 11(6), 471-482.

Dozier, J. B., \& Miceli, M. P. (1985). Potential predictors of whistle-blowing: A prosocial behavior perspective. Academy of Management Review, 823-836.

Dukerich, J. M., Nichols, M. L., Elm, D. R., \& Vollrath, D. A. (1990). Moral reasoning in groups: Leaders make a difference. Human Relations, 43(5), 473-493.

Dunning, D., Heath, C., \& Suls, J. M. (2004). Flawed self-assessment implications for health, education, and the workplace. Psychological science in the public interest, 5(3), 69-106.

Dunning, D., Leuenberger, A., \& Sherman, D. A. (1995). A new look at motivated inference: are self-serving theories of success a product of motivational forces?. Journal of Personality and Social Psychology, 69, 58-58.

Dunning, D., Meyerowitz, J. A., \& Holzberg, A. D. (1989). Ambiguity and self-evaluation: The 
role of idiosyncratic trait definitions in self-serving assessments of ability. Journal of Personality and Social Psychology, 57, 1082-1090.

Dutton, J. E., Ashford, S. J., O'Neill, R. M., \& Lawrence, K. A. (2001). Moves that matter: Issue selling and organizational change. Academy of Management Journal, 44(4), 716-736.

Dweck, C. S., Chiu, C., and Hong, Y. (1995). Implicit theories: Elaboration and extension of the model. Psychological Inquiry, 6, 322-333.

Eden, D. (1990). Pygmalion in management: Productivity as a self-fulfilling prophecy. Lexington Books/DC Heath and Com.

Eden, D., \& Shani, A. B. (1982). Pygmalion goes to boot camp: Expectancy, leadership, and trainee performance. Journal of Applied Psychology, 67(2), 194.

Ehrlinger, J., \& Dunning, D. (2003). How chronic self-views influence (and potentially mislead) estimates of performance. Journal of personality and social psychology, 84(1), 5-17.

Epley, N., \& Caruso, E. M. (2004). Egocentric ethics. Social Justice Research, 17(2), 171-187.

Feldman, J. M. (1981). Beyond attribution theory: Cognitive processes in performance appraisal. Journal of Applied psychology, 66(2), 127-148.

Fiske, S. T. (2002). Five core social motives, plus or minus five. In S. J. Spencer, S. Fein, M. P. Zanna, \& J. Olson (Eds.), Motivated social perception: The Ontario Symposium (Vol. 9, pp. 233-246). Mahwah, NJ: Erlbaum.

Flynn, F. J., \& Bohns, V. K. (2012). Underestimating one's influence in help-seeking. In D. T. Kenrick, N. Goldstein, \& S. L. Braver (Eds.), Six Degrees of Social Influence: Science, Application, and the Psychology of Robert Cialdini (pp. 14-26). New York: Oxford University Press. 
Flynn, F. J., \& Lake, V. K. B. (2008). If you need help, just ask: Underestimating compliance with direct requests for help. Journal of Personality and Social Psychology, 95, 128-143.

Furst, S. A., \& Cable, D. M. (2008). Employee resistance to organizational change: Managerial influence tactics and leader-member exchange. Journal of Applied Psychology, 93(2), 453.

Gailey, J. A., \& Lee, M. T. (2005). An integrated model of attribution of responsibility for wrongdoing in organizations. Social Psychology Quarterly, 68(4), 338-358.

Galinsky, A. D., Magee, J. C., Gruenfeld, D. H., Whitson, J. A., \& Liljenquist, K. A. (2008). Power reduces the press of the situation: Implications for creativity, conformity, and dissonance. Journal of personality and social psychology, 95(6), 1450.

Gibney, A. (2006). The Human Behavior Experiments.

Gibney, A. (2005). Enron: The smartest guys in the room.

Gilbert, D. T., \& Jones, E. E. (1986). Perceiver-induced constraint: Interpretations of selfgenerated reality. Journal of Personality and Social Psychology, 50, 269-280.

Gilbert, D. T., \& Malone, P. S. (1995). The correspondence bias. Psychological Bulletin, 117, $21-38$.

Gino, F., Ayal, S., \& Ariely, D. (2009). Contagion and differentiation in unethical behavior: The effect of one bad apple on the barrel. Psychological Science, 20, 393-398.

Gino, F., \& Galinsky, A. (2012). Vicarious dishonesty: When psychological closeness creates distance from one's own moral compass. Organizational Behavior and Human Decision Processes, 119, 15-26.

Gino, F., Sharek, Z., \& Moore, D. A. (2011). Keeping the illusion of control under control: Ceilings, floors, and imperfect calibration. Organizational Behavior and Human Decision 
Processes, 114, 104-114.

Gioia, D. A. (1992). Pinto Fires and Personal Ethics: A script analysis of missed opportunities. Journal of Business Ethics, 11, 379-398.

Gray, K., Knobe, J., Sheskin, M., Bloom, P., \& Barrett, L. F. (2011). More than a body: Mind perception and the nature of objectification. Journal of Personality and Social Psychology, 101, 1207-1220.

Green, S. G., \& Mitchell, T. R. (1979). Attributional processes of leaders in leader-member interactions. Organizational Behavior and Human Performance, 23(3), 429-458.

Gruenfeld, D., Inesi, E., Magee, J. \& Galinsky, A. (2008). Power and the objectification of social targets. Journal of Personality and Social Psychology, 95, 111-127.

Hamilton, V. L. (1980). Intuitive psychologist or intuitive lawyer? Alternative models of the attribution process. Journal of Personality and Social Psychology, 39, 767-772.

Hamilton, V. L.,\& Sanders, J. (1992). Responsibility and risk in organizational crimes of obedience. In B. M. Staw \& L. L. Cummings (Eds.), Research in organizational behavior (Vol. 14, pp. 49-90). Greenwich, CT: JAI Press.

Hannan, M. T., \& Freeman, J. (1984). Structural inertia and organizational change. American Sociological Review, 149-164.

Haslam, N. (2006). Dehumanization: An integrative review. Personality and social psychology review, 10(3), 252-264.

Heider, F. (1958). The psychology of interpersonal relations. Psychology Press.

Heider, F., \& Simmel, M. (1944). An experimental study of apparent behavior. The American Journal of Psychology, 57(2), 243-259.

Heller, F. A., \& Yukl, G. (1969). Participation, managerial decision-making, and situational 
variables. Organizational Behavior and Human Performance, 4(3), 227-241.

Herold, D. M. (1977). Two-way influence processes in leader-follower dyads. Academy of Management Journal, 20(2), 224-237.

Hollander, E. P. (1958). Conformity, status, and idiosyncrasy credit. Psychological Review, 65, $117-127$.

Hollander, E. P., \& Julian, J. W. (1970). Studies in leader legitimacy, influence, and innovation. Advances in experimental social psychology, 5, 33-69.

Hollander, E. P., \& Offermann, L. R. (1990). Power and leadership in organizations:

Relationships in transition. American Psychologist, 45(2), 179.

Hollander, E. P., \& Webb, W. B. (1955). Leadership, followership, and friendship: an analysis of peer nominations. Journal of abnormal psychology, 50(2), 163.

Jacobs, A. (November 17, 2012). "Grace Coddington is always in fashion.” New York Times.

Jones, E. E. \& Harris, V. A. (1967). "The attribution of attitudes". Journal of Experimental Social Psychology, 3, 1-24.

Jones, T. M., \& Ryan, L. V. (1998). The effect of organizational forces on individual morality: Judgment, moral approbation, and behavior. Business Ethics Quarterly, 431-445.

Judge, T. A., Locke, E. A., Durham, C. C. \& Kluger, A. N. (1998). Dispositional Effects on Job and Life Satisfaction: The Role of Core Evaluations. Journal of Applied Psychology, 83, 17-34.

Kanter, R. M. (2003). Challenge of organizational change: How companies experience it and leaders guide it. Simon and Schuster.

Kelman, H. C. \& Hamilton, V. L. (1989). Crimes of Obedience: Toward a social psychology of authority and responsibility. New Haven: Yale University Press. 
Kelley, H.H. (1971). Attribution in social interaction. Morristown, NJ: General Learning Press.

Kipnis, D., Castell, J., Gergen, M., \& Mauch, D. (1976). Metamorphic effects of power. Journal of Applied Psychology, 61(2), 127.

Kipnis, D., \& Schmidt, S. M. (1988). Upward-influence styles: Relationship with performance evaluations, salary, and stress. Administrative Science Quarterly, 528-542.

Kipnis, D., Schmidt, S. M., \& Wilkinson, I. (1980). Intraorganizational influence tactics: Explorations in getting one's way. Journal of Applied psychology, 65(4), 440.

Krueger, J., \& Clement, R. W. (1997). Estimates of social consensus by majorities and minorities: The case for social projection. Personality and Social Psychology Review, 1(4), 299-313.

Kruger, J. (1999). Lake Wobegon be gone! The" below-average effect" and the egocentric nature of comparative ability judgments. Journal of personality and social psychology, 77(2), 221.

Kruger, J., \& Dunning, D. (1999). Unskilled and unaware of it: How difficulties in recognizing one's own incompetence lead to inflated self-assessments. Journal of personality and social psychology, 77(6), 1121-1134.

Langer, E. J. (1975). The illusion of control. Journal of Personality and Social Psychology, 32, 311-328.

Langer, E. J. \& Roth, J. (1975). Heads I win, tails it's chance: The illusion of control as a function of the sequence of outcomes in a purely chance task. Journal of Personality and Social Psychology, 32, 951-955.

Latane, B., \& Darley, J. M. (1970). The unresponsive bystander: Why doesn't he help?. New York: Appleton-Century Crofts. 
Levine, J. (March 23, 2011). "Brand Anna." Wall Street Journal.

Lewin, K. (1951). Field theory in social science. D. Cartwright (Ed.). New York: Harper Bros., 1951.

Lewis, M. (2010). Liar's poker. WW Norton \& Company.

Locke, E. A., \& Schweiger, D. M. (1979). Participation in decision-making: One more look. Research in organizational behavior, 1(10), 265-339.

Lord, R. G., \& Smith, J. E. (1983). Theoretical, information processing, and situational factors affecting attribution theory models of organizational behavior. Academy of Management Review, 8(1), 50-60.

Lowery, B. J. Jacobsen B.S. \& DuCette J. (1993). Causal attribution, control, and adjustment to breast cancer. Journal of Psychosocial Oncology, 10(4) 41.

Magee, J. C., \& Galinsky, A. D. (2008). 8 Social Hierarchy: The Self- Reinforcing Nature of Power and Status. The Academy of Management Annals, 2(1), 351-398.

Markus, H. \& Kitayama, S. (1991). Culture and the self: Implications for cognition, emotion, and motivation. Psychological Review, 98, 224-253.

Marsden, P. V., \& Friedkin, N. E. (1993). Network studies of social influence. Sociological Methods \& Research, 22(1), 127-151.

Masuda, T., \& Kitayama, S. (2004). Perceived-induced constraint and attitude attribution in Japan and in the US: A case for cultural dependence of the correspondence bias. Journal of Experimental Social Psychology, 40, 409-416.

Mazar, N. \& Aggarwal, P. (2011). Greasing the palm: Can collectivism promote bribery? Psychological Science, 22, 843-848.

McKenna, F. P. (2011). It won't happen to me: Unrealistic optimism or illusion of control? 
British Journal of Psychology, 84, 39-50.

McLean, B. \& Elkind, P. (2003). The smartest guys in the room: The amazing rise and scandalous fall of Enron. New York: Portfolio.

Mechanic, D. (1962). Sources of power of lower participants in complex organizations. Administrative Science Quarterly, 349-364.

Miceli, M. P., Near, J. P., \& Schwenk, C. R. (1991). Who blows the whistle and why. Indus. \& Lab. Rel. Rev., 45, 113.

Miceli, M. P., Near, J. P., \& Dworkin, T. M. (2008). Whistle-blowing in organizations. Psychology Press.

Milgram, S. (1963). Behavioral Study of Obedience. Journal of Abnormal and Social Psychology, 67, 371-8.

Miller, D. T., \& McFarland, C. (1987). Pluralistic ignorance: When similarity is interpreted as dissimilarity. Journal of Personality and Social Psychology, 53(2), 298.

Miller, D. T., \& Ratner, R. K. (1998). The disparity between the actual and assumed power of self-interest. Journal of personality and social psychology, 74(1), 53.

Miller, D. T., \& Ross, M. (1975). Self-serving biases in the attribution of causality: Fact or fiction. Psychological bulletin, 82(2), 213-225.

Montague, A., \& Matson, F. (1983). The dehumanization of man. New York: McGraw-Hill.

Morgensen, G. (December 7, 2008). "Debt watchdogs: Tamed or Caught Napping?" New York Times.

Mowday, R. T. (1978). The exercise of upward influence in organizations. Administrative Science Quarterly, 137-156.

Near, J. P., \& Miceli, M. P. (1985). Organizational dissidence: The case of whistle-blowing. 
Journal of Business Ethics, 4(1), 1-16.

Newark, D., Flynn, F., \& Bohns, V. K. (2013). Once bitten, twice shy: The effect of a past refusal on expectations of future compliance. Forthcoming in Social Psychological and Personality Science.

Nolan, J. M., Schultz, P.W., Cialdini, R. B., Goldstein, N. J., \& Griskevicius, V. (2008). Normative social influence is underdetected. Personality and Social Psychology Bulletin, 34, 913-923.

Offerman, L. (2004). When followers become toxic. Harvard Business Review.

Paharia, N., Kassam, K. S., Greene, J. D. \& Bazerman, M. H. (2009). Dirty work, clean hands: The moral psychology of indirect agency. Organizational Behavior and Human Decision Processes, 2, 134-141.

Prentice, D. A., \& Miller, D. T. (1993). Pluralistic ignorance and alcohol use on campus: Some consequences of misperceiving the social norm. Journal of personality and social psychology, 64, 243-243.

Pronin, E. (2008). How we see ourselves and how we see others. Science, 320(5880), 1177-1180.

Pronin, E., Wegner, D. M., McCarthy, K. \& Rodriguez, S. (2006). Everyday magical powers: The role of apparent mental causation in the overestimation of personal influence. Journal of Personality and Social Psychology, 91, 218-231.

Reed, G.M., Taylor, S.E., \& Kemeny, M.E. (1993). Perceived control and psychological adjustment in gay men with AIDS. Journal of Applied Social Psychology, 23, 791-824.

Reger, R. K., Gustafson, L. T., Demarie, S. M., \& Mullane, J. V. (1994). Reframing the 
organization: Why implementing total quality is easier said than done. Academy of Management Review, 19(3), 565-584.

Rosenthal, R., \& Jacobson, L. F. (1968). Teacher expectations for the disadvantaged. Scientific American, 218(4), 19-23.

Ross, L. (1977). The intuitive psychologist and his shortcomings: Distortions in the attribution process. In L. Berkowitz (Ed.), Advances in experimental social psychology (vol. 10). New York: Academic Press.

Ross, L., Greene, D., \& House, P. (1977). The "false consensus effect": An egocentric bias in social perception and attribution processes. Journal of Experimental Social Psychology, 13(3), 279-301.

Rotter, J. (1966). Generalized expectancies for internal versus external control of reinforcements. Psychological Monographs, 80, Whole No. 609.

Sabini, J., Sipemann, M. \& Stein, P. (2001). The really fundamental attribution error in social psychological research. Psychological Inquiry, 12, 1-15.

Salancik, G. R., \& Meindl, J. R. (1984). Corporate attributions as strategic illusions of management control. Administrative Science Quarterly, 238-254.

Schulz, R. \& Decker, S. (1985). Long-term adjustment to physical disability: The role of social support, perceived control, and self-blame. Journal of Personality and Social Psychology, 48, 1162-1172.

Schweiger, D. M., \& Leana, C. R. (1986). Participation in decision making. Generalizing from laboratory to field settings, 147, 166.

Sherman, J. W., Lee, A. Y., Bessenoff, G. R., \& Frost, L. A. (1998). Stereotype efficiency reconsidered: Encoding flexibility under cognitive load. Journal of Personality and 
Social Psychology, 75(3), 589.

Shin, J., Taylor, M. S., \& Seo, M. G. (2012). Resources for Change: the Relationships of Organizational Inducements and Psychological Resilience to Employees' Attitudes and Behaviors toward Organizational Change. Academy of Management Journal, 55(3), 727748.

Simon, H. A. (1976). Administrative behavior (3rd ed.). New York: The Free Press.

Sirkin, H. L., Keenan, P., \& Jackson, A. (2005). The hard side of change management. Harvard Business Review, 83(10), 108.

Strickland, L. H. (1958). Surveillance and trust1. Journal of personality, 26(2), 200-215.

Swann Jr, W. B., \& Gill, M. J. (1997). Confidence and accuracy in person perception: Do we know what we think we know about our relationship partners. Journal of Personality and Social Psychology, 73(4), 747-757.

Taylor, F. W. (1947). Scientific Management. New York: Harper \& Row.

Taylor, S. E. \& Brown, J. D. (1988). Illusion and well-being: A social-psychological perspective on mental health. Psychological Bulletin, 103, 193-210.

Thomas, L. T., \& Ganster, D. C. (1995). Impact of family-supportive work variables on workfamily conflict and strain: A control perspective. Journal of Applied Psychology, 80, 615.

Thompson, S. C., Armstrong, W., \& Thomas, C. (1998). Illusions of control, underestimations, and accuracy: A control heuristic explanation. Psychological Bulletin, 123, 143-161.

Thompson, S. C., Nanni, C., \& Levine, A. (1994). Primary versus secondary and disease versus consequence-related control in HIV-positive men. Journal of Personality and Social Psychology, 64, 540-547. 
Trevino, L. K., \& Victor, B. (1992). Peer reporting of unethical behavior: A social context perspective. Academy of Management Journal, 38-64.

Triandis, H. C. (1995). Individualism and collectivism. San Francisco, CA: Westview Press.

Tyler, T. R., Boeckmann, R. J., Smith, H. J., \& Huo, Y. J. (1997). Social justice in a diverse society (p. 176). Boulder, CO: Westview Press.

Van Boven, L. (2000). Pluralistic ignorance and political correctness: The case of affirmative action. Political Psychology, 21(2), 267-276.

Vadera, A.K., Aguilera, R.V., Caza, B.B.(2009). Making sense of whistle-blowing's antecedents: Learning from research on identity and ethics programs. Business Ethics Quarterly, 19(4): 553-586.

Van Boven, L., Loewenstein, G., \& Dunning, D. (2005). The illusion of courage in social predictions: Underestimating the impact of fear of embarrassment on other people. Organizational Behavior and Human Decision Processes, 96, 130-141.

Van Boven, L., Loewenstein, G., Dunning, D., \& Nordgren, L. F. (2013). Changing Places: A Dual Judgment Model of Empathy Gaps in Emotional Perspective Taking. Advances in Experimental Social Psychology, 117-171.

Van de Ven, A. H. (1986). Central problems in the management of innovation. Management Science, 32(5), 590-607.

Victor, B., Trevino, L. K., \& Shapiro, D. L. (1993). Peer reporting of unethical behavior: The influence of justice evaluations and social context factors. Journal of Business Ethics, $12(4), 253-263$.

Ward, C.O., Zanna, M.P. \& Cooper, J. (1974) The nonverbal mediation of self-fulfilling 
prophecies in interracial interaction. Journal of Experimental Social Psychology, 10, $109-120$.

Wegner, D. M., Sparrow, B., \& Winerman, L. (2004). Vicarious agency: Experiencing control over the movements of others. Journal of personality and social psychology, 838-848.

Wu, S., \& Keysar, B. (2007). The effect of culture on perspective taking. Psychological science, 18(7), 600-606.

Yamaguchi, S., Gelfand, M., Ohashi, M. M., \& Zemba, Y. (2005). The cultural psychology of control: Illusions of personal versus collective control in the United States and Japan. Journal of Cross-Cultural Psychology, 36, $750-761$.

Yukl, G., \& Falbe, C. M. (1990). Influence tactics and objectives in upward, downward, and lateral influence attempts. Journal of Applied Psychology, 75(2), 132.

Zenger, J. \& Folkman, J. Why invest in LD? Leadership Excellence, 29, 13-13.

Zey-Ferrell, M., \& Ferrell, O. C. (1982). Role-set configuration and opportunity as predictors of unethical behavior in organizations. Human Relations, 35(7), 587-604. 